\title{
Unsuspected Klinefelter Syndrome Diagnosed during Oncologic Evaluation: A Case Series
}

\author{
Margaret M. Eberl, MD, Maria R. Baer, MD, Martin C. Maboney, MD, PhD, \\ Sheila N. J. Sait, PhD, AnneMarie W. Block, PhD, and \\ Carolyn D. Farrell, MS, CNP, CGC
}

\begin{abstract}
Klinefelter syndrome is an underdiagnosed chromosomal disorder that has significant implications for health and for medical management. This report presents 5 adult male patients diagnosed with previously unsuspected Klinefelter syndrome as a result of cytogenetic testing for suspected hematologic malignancies. This case series highlights the importance of maintaining a comprehensive and holistic approach to medical care. The medical, genetic, and psychosocial implications of the Klinefelter diagnosis are discussed. (J Am Board Fam Pract 2005;18:132-9.)
\end{abstract}

Affecting approximately 1 in 500 men, regardless of race, Klinefelter syndrome (KS) is the most common sex chromosome disorder. ${ }^{1-4}$ In the majority of cases, the karyotype is $47, \mathrm{XXY}$; however, variant syndromes such as 48,XXXY and mosaicism $(46, \mathrm{XY} / 47, \mathrm{XXY})$ account for $20 \%$ of cases. ${ }^{5,6}$ The 47,XXY karyotype (see Figure 1) usually results from an error of nondisjunction during parental gametogenesis. ${ }^{1,6}$ Fifty-three percent of Klinefelter cases are caused by paternal nondisjunction, whereas maternal meiotic I errors, maternal meiotic II errors, and somatic cell mitotic errors after fertilization account for $34 \%, 9 \%$, and $3 \%$ of cases, respectively. ${ }^{7}$ The phenotype associated with the Klinefelter karyotype results in male hypogonadism, androgen deficiency, and impaired spermatogenesis. ${ }^{1}$ Although some men may exhibit all the classic signs of small testes, gynecomastia, sparse

Submitted, revised, 29 October 2004.

From the Division of Cancer Prevention \& Population Sciences (MME, MCM), Leukemia Section, Department of Medicine (MRB), Clinical Cytogenetics Laboratory, Department of Pathology and Laboratory Medicine (SNJS, $\mathrm{AWB}$ ), and Clinical Genetics Service, Department of Cancer Genetics (CDF), Roswell Park Cancer Institute, Buffalo, NY, and Departments of Social \& Preventive Medicine and Family Medicine and the School of Public Health \& Health Professions, State University of New York at Buffalo (MME, MCM). Address correspondence to Margaret M. Eberl, MD, Division of Cancer Prevention \& Population Sciences, Roswell Park Cancer Institute, Carlton House, Elm and Carlton Streets, Buffalo, NY 14263 (e-mail: margaret.eberl@roswellpark.org).

This work was supported in part by grant ATAPM 02075-01 from the American Cancer Society. body hair, increased stature and infertility, the phenotypic expression of $\mathrm{KS}$ is widely variable, frequently leading to a delayed or missed diagnosis. ${ }^{1}$ Gonadotropin levels are elevated and testicular size is generally reduced as a result of fibrosis of the seminiferous tubules. ${ }^{8}$

Chromosome abnormalities may arise during the process of benign or malignant tumorigenesis. ${ }^{9}$ These abnormalities may confirm the presence of a clonal disorder; furthermore, they may assign diagnosis and prognosis. When it is uncertain whether a chromosome abnormality is associated with a neoplastic disorder or is constitutional, phytohemagglutinin (PHA)-stimulated peripheral blood lymphocytes are studied. ${ }^{10}$ Constitutional chromosome abnormalities include nondisease-associated pericentric inversions and Robertsonian translocations, as well as numerical chromosome disorders associated with altered phenotypes, such as Down syndrome (trisomy 21) and sex chromosome disorders. $^{6}$

We report 5 adult male patients diagnosed with previously unsuspected Klinefelter syndrome as a result of cytogenetic testing for suspected hematologic malignancies. A review of the Mitelman Database of Chromosome Aberrations in Cancer yielded 28 cases of KS in 25 references. ${ }^{11}$ The cases noted in the Mitelman Database serve to highlight possible associations of KS with various malignancies; however, they are not comprehensive reviews of the diagnostic implications and appropriate medical management and evaluation of KS pa- 


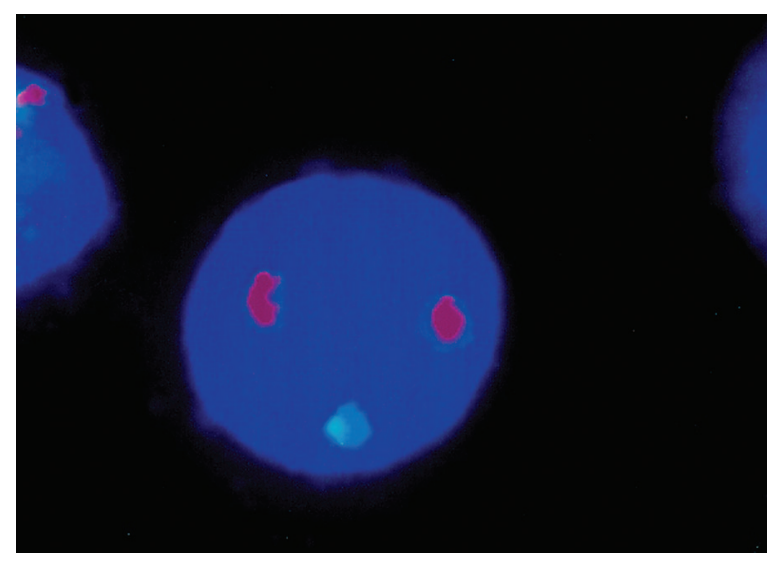

Figure 1. Centromere-specific enumeration probes (CEP X SpectrumOrange/CEP Y SpectrumGreen, Vysis, Inc., Downers Grove, IL) hybridized to interphase nucleus from PHA-stimulated peripheral blood sample demonstrating XXY karyotype.

tients. We summarize the 5 cases of unsuspected KS diagnosed in adulthood, highlighting 3 in particular, and we discuss the various implications of the KS diagnosis as well as the optimal management of these patients.

\section{Patient 1}

In October 2001, a 56-year-old man was referred for evaluation of thrombocytopenia. The patient reported 2 previous instances of low platelet counts noted on routine blood work and complained of feeling fatigued. Past medical history was significant for non-insulin-dependent diabetes mellitus, atrial fibrillation, emphysema, and major depression. The patient and his wife had adopted 2 children after experiencing infertility.

Bone marrow aspirate and biopsy completed as part of the diagnostic workup demonstrated normal hematopoiesis; the karyotype showed a 47,XXY genotype. The 47,XXY karyotype was also demonstrated in PHA-stimulated peripheral blood lymphocytes. The patient had been unaware of his genetic condition and, when informed, was not interested in extensive information regarding the diagnosis. Further consultation was completed with the Clinical Genetics service to more fully assess and discuss the implications of the diagnosis of KS. Endocrine testing, including testosterone, luteinizing hormone, and follicle stimulating hormone levels, and a bone scan were ordered, but the patient did not complete these tests and has been lost to follow-up.

\section{Patient 2}

In 1989, a 56-year-old man with a past medical history of mild retardation, major depression, alcohol abuse, and deep venous thrombosis was admitted with pancytopenia and fever of unknown origin. Physical examination at admission revealed a female pattern of hair distribution, gynecomastia, and atrophic testes. Bone marrow aspiration and biopsy established a diagnosis of acute myeloid leukemia; cytogenetic analysis revealed a 47,XXY karyotype. This karyotype was also later demonstrated in PHA-stimulated peripheral blood lymphocytes. The patient's leukemia was refractory to treatment. He had not been aware of his genetic condition, and it was not discussed with him. Endocrine testing was not completed.

\section{Patient 3}

In 1998, a 48-year-old man presented for evaluation and was diagnosed with non-Hodgkin lymphoma. Past history was significant for a selfdetected testicular mass 2 years before that had been diagnosed as an epididymal cyst; small testicular size had been documented at that time. He had also had chronic back pain, depression, and multiple dental caries. He and his wife had had no children, but his wife was reported to have had a miscarriage. He was tall and had long arms, but had a normal body build, a beard, and body hair, and did not have gynecomastia. Bone marrow testing demonstrated a 47,XXY karyotype in all cells, which was confirmed in PHA-stimulated peripheral blood lymphocytes.

The patient was referred to the Clinical Genetics Service and was counseled regarding the implications of the KS diagnosis. Given the history of miscarriage reported by his wife, this patient was informed that men with KS have occasionally fathered children. The patient was referred to an endocrinologist for consideration of testosterone supplementation. Unfortunately, he died from complications of his lymphoma later that year.

The features of these patients and of 2 additional patients who presented to our comprehensive cancer center between 1985 and 2001 for evaluation and management of known or suspected malignancies and were diagnosed with $\mathrm{KS}$ are summarized in Table 1. None of these men were aware of their chromosomal disorders at the time of presentation. 
Table 1. Clinical Highlights of Patients with Previously Unrecognized KS Diagnosed during Cytogenetic Testing

\begin{tabular}{|c|c|c|c|c|c|c|c|}
\hline Patient & $\begin{array}{c}\text { Age at } \\
\text { Presentation } \\
\text { (years) }\end{array}$ & Karyotype & $\begin{array}{c}\text { Initial } \\
\text { Diagnosis }\end{array}$ & $\begin{array}{c}\text { Final } \\
\text { Diagnosis }\end{array}$ & $\begin{array}{l}\text { Physical Findings } \\
\text { Relevant to KS }\end{array}$ & $\begin{array}{l}\text { Marital Status, } \\
\text { Children }\end{array}$ & Other \\
\hline 1 & 56 & $47, \mathrm{XXY}$ & $\begin{array}{l}\text { Thrombo- } \\
\text { cytopenia }\end{array}$ & $\mathrm{ITP}^{*}$ & Tall with long legs & $\begin{array}{l}\text { Married, two } \\
\text { adopted children }\end{array}$ & $\begin{array}{l}\text { Alcoholism, drug } \\
\text { addiction, } \\
\text { depression, } \\
\text { NIDDM }\end{array}$ \\
\hline 2 & 56 & $47, \mathrm{XXY}$ & AML & AML & $\begin{array}{l}\text { Gynecomastia, } \\
\text { atrophic testes, } \\
\text { female pattern of } \\
\text { hair distribution }\end{array}$ & $\begin{array}{l}\text { Never married, no } \\
\text { children }\end{array}$ & $\begin{array}{l}\text { Major depression, } \\
\text { alcoholism, mild } \\
\text { retardation, } \\
\text { NIDDM, venous } \\
\text { thromboembolism }\end{array}$ \\
\hline 3 & 48 & $47, \mathrm{XXY}$ & NHL & $\begin{array}{l}\text { NHL, diffuse } \\
\text { large cell }\end{array}$ & $\begin{array}{l}\text { Small, atrophic testes; } \\
\text { tall, long arms; no } \\
\text { gynecomastia; } \\
\text { normal beard, body } \\
\text { hair, \& apparent } \\
\text { build (yet pt } \\
\text { indicated increased } \\
\text { central fat, even as } \\
\text { child) }\end{array}$ & $\begin{array}{l}\text { Widower; wife had } \\
\text { history of } 1 \\
\text { miscarriage }\end{array}$ & $\begin{array}{l}\text { Chronic back pain, } \\
\text { infertility, } \\
\text { depression, } \\
\text { multiple dental } \\
\text { caries }\end{array}$ \\
\hline 4 & 67 & $47, \mathrm{XXY}$ & CLL & CLL & Gynecomastia & Married, 1 stepson & $\begin{array}{l}\text { Back pain, 8th grade } \\
\text { education, } \\
\text { NIDDM, dementia }\end{array}$ \\
\hline 5 & 56 & $47, \mathrm{XXY}$ & CML & CML & None noted & $\begin{array}{l}\text { Married, "3 healthy } \\
\text { sons" }\end{array}$ & $\begin{array}{l}\text { No mention of KS in } \\
\text { patient's records; } \\
\text { only in cytogenetic } \\
\text { report }\end{array}$ \\
\hline
\end{tabular}

* ITP, idiopathic thrombocytopenic purpura; NIDDM, non-insulin-dependent diabetes mellitus; AML, acute myeloid leukemia; NHL, non-Hodgkin lymphoma; CLL, chronic lymphocytic leukemia; CML, chronic myelogenous leukemia.

\section{Discussion}

\section{Issues of Diagnosis}

As these cases illustrate, patients with KS, especially those who do not exhibit the syndrome's classic physical features, may elude diagnosis until karyotyping is performed for other reasons. Three of our 5 patients were born before Klinefelter et $\mathrm{al}^{12}$ described the clinical syndrome in 1942 and long before the XXY karyotype was described in 1959; furthermore, routine karyotyping of bone marrow aspirates in oncology did not begin until the early 1980s, after high-resolution banding techniques were introduced. ${ }^{6,8,13}$ However, the other 2 patients eluded diagnosis despite birth after 1942 and the availability of cytogenetic analysis since the 1960s. Primary care clinicians are not only likely to underestimate the prevalence of KS in their patient populations but also less apt to consider genetic conditions in their older adult patients. ${ }^{5}$

Testosterone levels in affected persons may be in the low normal or normal ranges, making a diagnosis of KS even more challenging. Because the most consistent physical feature of KS is small, atrophic testes, it has been suggested that a testic- ular examination be part of a complete physical in school-age boys. ${ }^{1}$ This might be accomplished during annual health assessments in childhood/adolescence and as part of routine school-age physical examinations. Likewise, adult males presenting with a history of infertility should have testicular examinations performed.

It is imperative that family physicians become familiar with the more common genetic conditions and their potential manifestations at different ages to expedite diagnosis and treatment. ${ }^{5}$ To be considered common, a disease should occur with a frequency of one affected person per 1000 population. ${ }^{6}$ In addition to KS, other examples of common genetic conditions include Down syndrome and Turner syndrome. ${ }^{6}$

\section{Implications for Medical Oncology and Primary Care}

When KS is discovered during evaluation of a suspected or established malignancy, there are implications for the entire medical team, including both specialty and primary care physicians caring for the patient. A number of conditions are associated with 
$\mathrm{KS}$, including autoimmune disorders such as systemic lupus erythematosus and rheumatoid arthritis, diabetes mellitus, venous thromboembolic diseases, taurodontism (an uncommon condition of the teeth which predisposes to early decay), learning disabilities, psychiatric conditions such as anxiety and depression, or other more subtle manifestations of learning or behavior problems. In addition, patients with Klinefelter syndrome are at increased risk for both breast cancer and extragonadal germ cell tumors. ${ }^{1}$ When KS is determined to be present, the family physician is well positioned to monitor for other medical conditions.

Symptoms and signs of hypogonadism are often present, including fatigue, weakness, gynecomastia, osteoporosis, and infertility. ${ }^{1}$ The oncologist must differentiate cancer-related symptoms and conditions from those that are secondary to KS. Given the multitude of competing issues related to cancer treatment, specialty and primary care physicians should communicate regarding the best strategy for completing endocrine evaluation and possibly initiating hormone treatment. Effective communication with the patient's primary care physician may expedite and facilitate this process and assure that all facets important to medical and psychosocial care are addressed.

Awareness of the presence of KS can aid both the patient and his physicians in understanding manifestations of his disease and anticipating potential complications. ${ }^{1}$ For example, patient 3 (Table 1), with non-Hodgkin lymphoma, had continued back pain that was attributed to his malignancy. Although the oncology team caring for the patient was aware of his genetic abnormality, osteoporosis secondary to low testosterone levels was never considered as a cause of his back pain.

\section{Ethical Implications}

Any genetic testing performed as part of a malignancy work-up, including cytogenetic analysis, has the potential to reveal a constitutional genetic abnormality such as KS. This possibility raises the issue of informed consent and professional liability. Before bone marrow cytogenetic testing, oncologists should inform patients that, in rare instances, these studies identify as yet undiagnosed constitutional chromosome anomalies that may or may not have medical significance. Patients should be assured that a genetic counselor will be available to discuss any unexpected results. Moreover, patients should be told that awareness and understanding of such conditions can have a positive impact on overall health. Patients should be informed of all results, unless during pretest counseling the patient has expressed a desire to not know any additional genetic diagnoses. Medical records must document genetic findings, as well as highlights of consequent conversations and decisions about evaluation and management. As noted above, the primary care clinician should also be informed of karyotype results and should be involved in management.

\section{Psychosocial Implications}

Contributing to feelings of distress associated with the diagnosis of KS are the psychosocial implications, which have an effect not only on the patient but also on his family and friends. Although men with mosaic KS karyotypes may rarely be fertile, most men with KS are absolutely infertile as a result of testicular failure. ${ }^{1}$ For those $47, \mathrm{XXY}$ males who have children, a diagnosis of KS can be devastating in that the paternity of their children comes into question. The fact that one of the 5 men in this series was married and was reported to be the father of 3 children and the wife of another patient had reportedly had a miscarriage may illuminate the challenging personal issues resulting from the diagnosis. Clinicians must approach these cases sensitively and individually. Those men who have not had children may either have been told that they (and/or their partners) are infertile or may not be aware of their infertility. The diagnosis of KS has the potential to complicate personal relationships. On the other hand, some men may ultimately feel relieved to know that their infertility and other possible symptoms have a cause.

Psychological or psychiatric evaluation should be offered to all patients with KS because they may be at increased risk of anxiety, depression, and psychoses. ${ }^{1} \mathrm{XXY}$ men rate themselves as being more sensitive and insecure and less sexually interested in women compared with age-matched control subjects. ${ }^{14}$

\section{Genetic Implications}

Individuals with KS and their families should be counseled regarding the fact that the KS karyotype arises spontaneously. ${ }^{8}$ The siblings of a patient with KS have the same risk ( 1 in 500 male births affected) as the general population. ${ }^{1} \mathrm{KS}$ patients should be informed that no clear etiologic factors 
have been identified. ${ }^{6}$ It has been suggested that advanced maternal age increases the risk of 47,XXY births, with a maternal age of 40 years being associated with a risk 2 to 3 times greater than that associated with a maternal age of $30 .{ }^{15,16}$ Although KS patients are generally infertile, a patient with mosaic KS may have children as a result of preserved testicular function. In these cases, there is an increased likelihood of having a child with a chromosomal imbalance involving the $\mathrm{X}$ chromosome. ${ }^{17-19}$

New developments in assisted reproductive technologies, such as testicular sperm extraction and intracytoplasmic sperm injection, may offer men with nonmosaic KS and their partners the possibility of conception. ${ }^{20}$ However, healthy deliveries after these procedures are rare, and concern regarding the possibility of transmitting chromosomal abnormalities exists. ${ }^{20}$

\section{Medical Management and Surveillance}

Once a diagnosis of KS has been confirmed, issues of appropriate medical management, patient education, and screening arise (Table 2). Although there is limited scientific evidence to support these recommendations, they are presented because (1) high-quality evidence is impossible to obtain and (2) the anticipated benefits outweigh harms. Clinicians should be flexible in their decision-making regarding appropriate management; patient preference should also be considered. Clinicians should always act and decide in a way that they believe will best serve the needs of their patients.

The androgen deficiency that is characteristic of KS places these men at increased risk for osteoporosis. ${ }^{1,21}$ In a series of 22 men with KS, $25 \%$ had measurable osteopenia that was probably caused by decreased bone formation and increased bone resorption. ${ }^{22}$ The incidence of osteoporosis and the actual fracture rate in these patients has not been reported. Testosterone supplementation before age 20 can restore bone mass to normal levels, and supplementation after age 20 may thwart additional bone loss, thereby preventing fractures in older patients with KS. ${ }^{1}$ All adult men with KS should undergo bone mineral density testing. ${ }^{5}$ Testosterone supplementation may also have additional positive effects on mood and self-esteem. ${ }^{1}$

Karyotyping of men with breast cancer has shown that men with KS have an increased risk of developing this malignancy. ${ }^{23}$ In a retrospective study of 93 unselected male breast cancer patients, $7.5 \%$ had KS. This prevalence is double that cited in previous studies, possibly because of these authors' use of fluorescence in situ hybridization with $\mathrm{X}$ and $\mathrm{Y}$ chromosome-specific DNA probes. Men with Klinefelter syndrome have up to 50 times the risk of breast cancer compared with men with normal karyotypes. ${ }^{24}$ Gynecomastia seems to be a predisposing factor for these cases. ${ }^{1}$ Although routine mammography is not recommended, it has been suggested that KS patients with gynecomastia perform breast self-examinations. ${ }^{5}$ However, this recommendation may be questioned in view of the recent reports that breast self-examination may not be effective in women. ${ }^{25,26}$ Current evidence supports the value of annual mammography among women for mortality reductions. ${ }^{27-29}$

Although rare in the general population, extragonadal germ cell tumors occur with increased frequency in patients with KS. ${ }^{8}$ The relative risk of mediastinal germ cell tumors is 67 times higher in men with KS. ${ }^{30}$ Elevation of gonadotropin levels may lead to germ cell transformation. ${ }^{1}$ From early adolescence to age 30, men with KS have a substantially increased incidence of mediastinal germ cell tumors. ${ }^{30}$ If young men with KS experience

Table 2. Issues of Medical Management and Surveillance among Patients with KS

\begin{tabular}{ll}
\hline Medical Issue & Management Strategy \\
\hline Hypogonadism & Discuss risks and benefits of testosterone supplementation \\
Osteopenia/osteoporosis & Bone mineral density testing \\
Gynecomastia/breast cancer risk & Consider breast self-examination instruction \\
$\begin{array}{l}\text { Diabetes mellitus } \\
\text { Learning disabilities }\end{array}$ & Counseling for nutrition, exercise \\
Psychiatric/psychological conditions & Formal testing \\
Dental caries & Evaluation and treatment \\
\hline
\end{tabular}


otherwise unexplained respiratory symptoms, they should undergo radiographic evaluation. ${ }^{30}$

A cohort of 646 men with KS having a 47,XXY constitution had significantly increased overall mortality [risk ratio $(\mathrm{RR})=1.63$; confidence interval $(\mathrm{CI})=1.40$ to 1.91 ] and increased mortality from lung cancer $(\mathrm{RR}=2.45 ; \mathrm{CI}=1.55$ to 3.67$)$ and breast cancer $(\mathrm{RR}=61.7 ; \mathrm{CI}=7.47$ to 227.7). ${ }^{23}$ Information on smoking habits was not obtained as part of this study, leaving open the possibility that these men smoked more than the general population. In addition, a total of 2 breast cancer deaths was observed. ${ }^{23}$

Many medical textbooks and several case reports suggest an association between KS and leukemia and lymphoma; however, this association has not been proven. A cohort study of 696 men with KS found no difference in the incidence of leukemia and lymphoma. ${ }^{30} \mathrm{~A}$ review of 1200 consecutive patients who underwent cytogenetic evaluation for hematologic malignancies identified only one patient with the combination of acute leukemia and a $47, \mathrm{XXY}$ genotype. ${ }^{31}$ In cytogenetic studies of bone marrow samples from 5366 patients with hematologic malignancies, 22 cases of constitutional sex chromosome aneuploidy were identified; 6 of these 22 patients had karyotypes consistent with KS. ${ }^{32}$ Among these 6, 3 had myelodysplastic syndrome (MDS), 2 had non-Hodgkin lymphoma (NHL), and one had acute myeloid leukemia (AML). Overall, these authors identified a total of 66 cases of hematologic malignancies in patients with KS reported in the published literature. ${ }^{32}$ Among these 66 cases, AML (23\%) and NHL (23\%) were most frequent, followed by acute lymphocytic leukemia (18\%) and MDS (17\%). ${ }^{32}$ The fact that patients with leukemia and lymphoma have a greater likelihood of undergoing cytogenetic testing may lead to the appearance of an association between KS and hematologic malignancy. ${ }^{30}$ It has been suggested that any apparent association between constitutional karyotype abnormalities and hematologic malignancies is probably a random phenomenon. ${ }^{32}$

Because patients with $\mathrm{KS}$ are at increased risk for autoimmune disorders, family physicians need to investigate any symptoms that may be indicative of these conditions. For example, the prevalence of type 1 diabetes mellitus is increased in KS, with $8 \%$ of patients affected. However, the onset of diabetes mellitus in KS is more gradual and symptoms are usually milder, as in adult onset diabetes. ${ }^{1,33}$ It has been reported that plasma testosterone concentrations are inversely related to insulin resistance $(\mathrm{r}=0.58, P=.019) .{ }^{34}$ Patients with KS should be encouraged to maintain or increase their physical activity to control blood sugar levels and maintain a healthy weight.

Physical activity will also serve to improve circulation, thereby reducing the occurrence of venous stasis complications, including venous thromboembolic events (deep vein thrombosis and pulmonary embolus), which occur with increased frequency in KS, and venous ulcers, which are 10 to 20 times more prevalent. ${ }^{1,35}$ Smoking cessation should be emphasized, not only to potentially prevent vascular complications arising from diabetes but also to prevent lung cancer, which contributes to increased overall mortality. ${ }^{23}$

It has also been suggested that men with KS be evaluated for specific learning disabilities. ${ }^{5} \mathrm{Al}$ though overall intelligence may be within normal range, it has been noted that KS patients tend to have deficits in verbal and motor skills. ${ }^{14}$ Finally, routine dental care should be arranged, because more than $40 \%$ of patients with KS experience accelerated tooth decay, predisposing to dental caries. $^{1}$

\section{Conclusion}

Occurring in all racial groups, KS is one of the most common chromosome disorders in humans and is also the leading cause of hypogonadism and infertility in men. ${ }^{6,33}$ Because of its varied phenotypic expression and the low index of suspicion that many health care professionals have toward genetic diagnoses in adults, the diagnosis of KS is often not made until problems with fertility arise or karyotyping is performed for other reasons. ${ }^{1}$

In the 5 cases discussed here, the abnormal karyotype was discovered in bone marrow aspirates performed during work-up for hematologic malignancies. The discovery of underlying genetic abnormalities such as KS has important implications for both the patient and the medical team caring for the patient. Genetic, ethical/legal and psychosocial issues must be addressed and documented, and subsequent medical management must be tailored to each patient. Several screening and prevention considerations apply to these patients. Communication between medical specialists, genetics professionals, and primary care physicians becomes essential in 
optimizing patient care. Prompt diagnosis and discussion benefit the patient, who will receive care that is suited to his special needs.

\section{References}

1. Smyth CM, Bremner WJ. Klinefelter syndrome. Arch Intern Med Jun 22 1998;158:1309-14.

2. Nielsen J, Wohlert M. Sex chromosome abnormalities found among 34,910 newborn children: results from a 13-year incidence study in Arhus, Denmark. Birth Defects Orig Artic Ser 1990;26:209-23.

3. Hamerton JL, Canning N, Ray M, Smith S. A cytogenetic survey of 14,069 newborn infants. I. Incidence of chromosome abnormalities. Clin Genet Oct 1975;8:223-43.

4. Maclean N, Harnden DG, Brown WM, Bond J, Mantle DJ. Sex-chromosome abnormalities in newborn babies. Lancet 1964;13:286-90.

5. Tyler CV Jr, Kungl PA, Green LA. Genetic diagnosis in adulthood. A case report. J Fam Pract 1998;47: 227-30.

6. Wiesner G, Everman D, Cassidy S. Constitutional Chromosome Disorders in Adults. In: The Genetic Basis of Common Diseases (King R, Rotter J, Motulsky A, editors), 2nd ed. Oxford: Oxford University Press Inc; 2002. p. 989-1019.

7. Jacobs PA, Hassold TJ, Whittington E, et al. Klinefelter's syndrome: an analysis of the origin of the additional sex chromosome using molecular probes. Ann Hum Genet May 1988;52:93-109.

8. Smyth CM. Diagnosis and treatment of Klinefelter syndrome. Hosp Pract (Off Ed) Sep 15 1999;34: 111-2, 115-6, 119-20.

9. Block AW. Cancer cytogenetics. In: The principles of clinical cytogenetics (Gersen S, Keagle M, editors). Totowa (NJ): Humana Press Inc.; 1999. p. 345-420.

10. Baer M. Cytogentics. In: Wintrobe's clinical hematology (Lee G, editor), vol. 1, 10th ed. Baltimore: Lippincott Williams \& Wilkins; 1999. p. 98-123.

11. Mitelman F, Johansson B, Mertens F. Mitelman database of chromosome aberrations in cancer [database on the Internet]. Bethesda (MD): National Cancer Institute. c2004 - [cited 2004 Oct 29]. Available from: http://cgap.nci.nih.gov/Chromosomes/ Mitelman.

12. Klinefleter HF, Reifenstein EC Jr, Albright F. Syndrome characterized by gynecomastia, aspermatogenesis with a Leydigism and increased excretion of follicle-stimulation hormone. J Clin Endocrinol Metab 1942;2:615-27.

13. Jacobs PA, Strong JA. A case of human intersexuality having a possible XXY sex-determining mechanism. Nature 1959;183:302-3.

14. Mandoki MW, Sumner GS, Hoffman RP, Riconda DL. A review of Klinefelter's syndrome in children and adolescents. J Am Acad Child Adolesc Psychiatry 1991;30:167-72.

15. Carothers AD, Filippi G. Klinefelter's syndrome in Sardinia and Scotland. Comparative studies of parental age and other aetiological factors in 47,XXY. Hum Genet 1988;81:71-5.

16. Bojesen A, Juul S, Gravholt CH. Prenatal and postnatal prevalence of Klinefelter syndrome: a national registry study. J Clin Endocrinol Metab 2003;88: 622-6.

17. Foresta C, Galeazzi C, Bettella A, Stella M, Scandellari C. High incidence of sperm sex chromosomes aneuploidies in two patients with Klinefelter's syndrome. J Clin Endocrinol Metab 1998;83:203-5.

18. Rives N, Joly G, Machy A, Simeon N, Leclerc P, Mace B. Assessment of sex chromosome aneuploidy in sperm nuclei from 47,XXY and 46,XY/47,XXY males: comparison with fertile and infertile males with normal karyotype. Mol Hum Reprod Feb 2000; 6:107-12.

19. Blanco J, Egozcue J, Vidal F. Meiotic behaviour of the sex chromosomes in three patients with sex chromosome anomalies $(47, \mathrm{XXY}$, mosaic 46,XY/47,XXY and 47,XYY) assessed by fluorescence in-situ hybridization. Hum Reprod 2001;16:887-92.

20. Ulug U, Bener F, Akman MA, Bahceci M. Partners of men with Klinefelter syndrome can benefit from assisted reproductive technologies. Fertil Steril Oct 2003;80:903-6.

21. Luisetto G, Mastrogiacomo I, Bonanni G, et al. Bone mass and mineral metabolism in Klinefelter's syndrome. Osteoporos Int 1995;5:455-61.

22. Horowitz M, Wishart JM, O'Loughlin PD, Morris HA, Need AG, Nordin BE. Osteoporosis and Klinefelter's syndrome. Clin Endocrinol (Oxf) 1992; 36:113-8.

23. Swerdlow AJ, Hermon C, Jacobs PA, et al. Mortality and cancer incidence in persons with numerical sex chromosome abnormalities: a cohort study. Ann Hum Genet Mar 2001;65:177-88.

24. Hultborn R, Hanson C, Kopf I, Verbiene I, Warnhammar E, Weimarck A. Prevalence of Klinefelter's syndrome in male breast cancer patients. Anticancer Res 1997;17:4293-7.

25. Thomas DB, Gao DL, Ray RM, et al. Randomized trial of breast self-examination in Shanghai: final results. J Natl Cancer Inst 2002;94:1445-57.

26. Semiglazov VF, Moiseenko VM, Uzunova VG, Migmanova N, Popova RT. Results of phase I study of the effectiveness of self-examination in a program of early detection of breast cancer. Vopr Onkol 1985; 31:18-25.

27. Berg AO, Allan J, Woolf S. The mammography dilemma. Ann Intern Med May 6 2003;138:770-1; author reply 771 .

28. Screening for breast cancer: recommendations and rationale. Ann Intern Med 2002;137:344-6.

29. United States Preventive Services Task Force. 
Screening for breast cancer: recommendations and rationale [monograph on the Internet]. Rockville (MD): Agency for Healthcare Research and Quality; 2002 [cited 2004 Feb 24]. Available from: http:// www.ahrq.gov/clinic/3rduspstf/breastcancer/brcanrr. htm.

30. Hasle H, Mellemgaard A, Nielsen J, Hansen J. Cancer incidence in men with Klinefelter syndrome. Br J Cancer 1995;71:416-20.

31. Horsman DE, Pantzar JT, Dill FJ, Kalousek DK. Klinefelter's syndrome and acute leukemia. Cancer Genet Cytogenet 1987;26:375-6.

32. Welborn J. Constitutional chromosome aberrations as pathogenetic events in hematologic malignancies. Cancer Genet Cytogenet 2004;149:137-53.

33. Connor M, Ferguson-Smith M. Essential medical genetics, 5th ed. Oxford: Blackwell Science Ltd; 1984.

34 Pei D, Sheu WH, Jeng CY, Liao WK, Fuh MM. Insulin resistance in patients with Klinefelter's syndrome and idiopathic gonadotropin deficiency. J Formos Med Assoc 1998;97:534-40.

35 Veraart JC, Hamulyak K, Neumann HA. Leg ulcers and Klinefelter's syndrome. Arch Dermatol 1995; 131:958-9. 